\title{
The aspirin papers
}

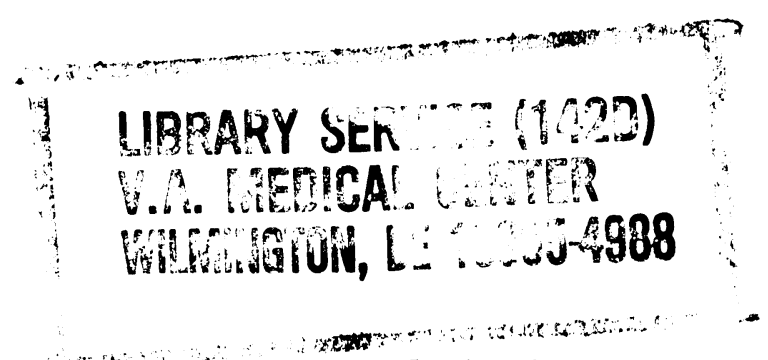

\section{Aspirin benefits patients with vascular disease and those undergoing revascularisation}

Over the next three weeks the journal is devoting 50 pages to overviews prepared by the Antiplatelet Trialists' Collaboration. ${ }^{1-3}$ Altogether, some 300 randomised controlled trials assessing the potential benefits of antiplatelet treatment are considered. This editorial and the next one, by George Davey Smith and Matthias Egger, ${ }^{4}$ discuss some of the clinical and methodological implications of these landmark papers.

The first paper ( $p$ 81) ${ }^{1}$ reviews the efficacy of such treatments in preventing death, myocardial infarction, and stroke in patients with documented atherosclerosis (for example, unstable angina, or previous myocardial infarction, transient ischaemic attack, or stroke). This large overview confirms that antiplatelet treatment reduces vascular events by about a quarter in these high risk patients. Non-fatal myocardial infarction and stroke are reduced by one third; vascular deaths (from fatal myocardial infarction and stroke) fall by one sixth.

In this heterogeneous group of patients these benefits are apparent irrespective of age, sex, blood pressure, or the presence of diabetes. Aspirin alone, at doses ranging from $75 \mathrm{mg}$ to $325 \mathrm{mg}$, seems as effective as any other antiplatelet regimen, with little risk of adverse side effects (such as gastrointestinal or intracerebral haemorrhage). The most effective dose of aspirin for long term treatment still needs to be determined, but in emergencies-for example, acute myocardial infarction - a daily dose of at least $160 \mathrm{mg}$ to ensure a rapid onset of action seems sensible. ${ }^{5}$ The optimum duration of treatment in this group of patients is unknown as the trials analysed lasted only two years on average, but lifelong treatment may be advantageous unless specific contraindications exist.

The first overview also considered the effect of antiplatelet treatment on low risk subjects-those with no history of vascular events. Benefits were difficult to show, possibly because of the low overall incidence of vascular events, ${ }^{4}$ (and because a few cerebral haemorrhages may have been caused), although the risk of non-fatal myocardial infarction fell by 5 per 1000 treated cases. Until further work has been carried out the routine use of antiplatelet treatment for primary prevention cannot be recommended. ${ }^{6}$

In patients undergoing revascularisation procedures, antiplatelet agents have been extensively investigated, although a standard protocol for coronary artery bypass surgery is still lacking. ${ }^{7}$ This may reflect the fact that all published trials have used different inclusion and exclusion criteria and have assessed patency of the graft at different times postoperatively. In addition, factors other than adjuvant treatment influence the development of occlusion of the graft (for example, the diameter of grafted vessels and distal artery run off). An overview of all these trials is therefore helpful in providing some practical recommendations for treatment.

\section{Aspirin enhances patency of grafts}

Conclusive evidence exists that antiplatelet treatment enhances the early patency of coronary vein grafts. Aspirin alone seems as effective as any other agent, with a dose of $325 \mathrm{mg}$ as beneficial as higher doses. Lower doses may be as efficacious, but no trial has shown this directly. To be effective, treatment should be started early after the procedure, as indicated by a previous meta-analysis, ${ }^{8}$ and indeed the trials that have failed to show benefit with treatment have been those in which antiplatelet treatment was delayed until the second or third postoperative day. ${ }^{910}$ Preoperative treatment increases the risk of bleeding, ${ }^{11}$ but administration within six hours after operation seems safe and effective. ${ }^{12}$ Again the question of the duration of treatment arises. At least one year's treatment reduces new lesions in vein grafts, ${ }^{13}$ but these patients also have residual native coronary atheroma and, as this week's paper suggests, may therefore benefit from more prolonged treatment.

Patients undergoing peripheral vascular procedures accrue similar benefits in terms of graft patency. ${ }^{2}$ What is unclear, however, is which cohort of patients benefits most. Debate continues over the need to treat patients with peripheral saphenous vein (as opposed to prosthetic) grafts, ${ }^{14}$ but, although treatment may not enhance survival of the graft, it may still reduce the incidence of subsequent vascular events in these patients with generalised atherosclerotic disease (two thirds of these patients will die of cardiovascular or cerebrovascular events ${ }^{15}$ ). No trial has addressed this issue. Antiplatelet treatment is now routinely given during coronary angioplasty, although only a few prospective studies have been carried out. Of the studies reviewed, each used a different antiplatelet agent, but similar falls in rates of acute thrombosis (by about half) were observed in the two larger trials.

The effect of antiplatelet treatment on the incidence of venous thromboembolism is not widely appreciated. The third review shows that in trials in which deep vein thrombosis was assessed systematically, antiplatelet treatment sig- 
nificantly reduced its incidence. ${ }^{3}$ Importantly, in this group of patients (those undergoing general surgical and orthopaedic procedures, and at risk and immobile medical patients) the incidence of pulmonary embolism fell significantly. The review does not suggest that antiplatelet agents should replace subcutaneous heparin for routine prophylaxis, but, interestingly, the combination of heparin and an antiplatelet agent may be better than heparin alone in preventing pulmonary embolism. This conclusion is based on a small number of trials, and further studies are clearly needed to determine the exact role of antiplatelet treatment in this group of patients.

These three major overviews of the use of antiplatelet treatment in various groups of patients provide valuable information on which to base clinical practice; they also highlight topics requiring further investigation. Patients with established atherosclerosis (affecting their cardiac, cerebral, or peripheral arteries) benefit in terms of fewer subsequent vascular events. Patients undergoing revascularisation procedures (coronary grafting, peripheral grafting, and angio-

1 Antiplatelet Trialists' Collaboration. Collaborative overview of randomised trials of antiplatelet treatment. I. Prevention of death, myocardial infarction, and stroke by prolonged antiplatelet therapy in various categories of patients. BMF 1994;308:81-106.

2 Antiplatelet Trialists' Collaboration. Collaborative overview of randomised trials of antiplatelet treatment. II. Maintenance of vascular graft or arterial patency by antiplatelet therapy. $B M \mathcal{F}$ 1994;308(in press).

3 Antiplatelet Trialists' Collaboration. Collaborative overview of randomised trials of antiplatelet treatment. III. Reduction in venous thrombosis and pulmonary embolism by antiplatelet prophylaxis among surgical and medical patients. BMY 1994;308(in press).

prophylaxis among surgical and medical patients. $B M \mathcal{F} 1$ 1994;308(in press).
Davey-Smith G, Egger $M$. Who benefits from medical interventions? BMF 1994;308:72-4.

4 Davey-Smith G, Egger M. Who benefits from medical interventions? BMf 1994;308:72-4.
5 ISIS-2 (Second International Study of Infarct Survival) Collaborative Group. Randomised trial of intravenous streptokinase, oral aspirin, both, or neither among 17187 cases of suspected acute myocardial infarction: ISIS-2. Lancet 1988;ii:349-60.

6 Willard JE, Lange RA, Hillis LD. The use of aspirin in ischemic heart disease. $N$ Engl 9 Med 1992;327:175-81.

7 Angelini GD, Bryan AJ, West RR, Newby AC, Brekenridge IM. Coronary artery bypass surgery: current practice in the United Kingdom. Thorax 1989;44:721-4.

8 Henderson WG, Goldman S, Copeland JG, Moritz TE, Harker LA. Antiplatelet or anticoagulant therapy after coronary artery bypass surgery. A meta-analysis of clinical trials. Ann Intern Med 1989;111:743-50. plasty) also benefit in terms of better patency of the vessel and fewer vascular events unrelated to the procedure. The role of antiplatelet treatment in prophylaxis against venous thromboembolism is less certain as other effective treatment (subcutaneous heparin) exists. ${ }^{16}$

In all groups of patients aspirin, at a dose of 75-325 mg, seems as effective as any other single agent or combination of agents. The duration of treatment still needs to be determined, but for those with established atherosclerosis lifelong treatment may be indicated. For patients without clinically apparent atherosclerotic disease the potential haemorrhagic complications of routine use of aspirin may outweigh its benefit.

M J UNDERWOOD British Heart Foundation research fellow

R S MORE British Heart Foundation research fellow

Department of Academic Cardiology,

Glenfield General Hospital,

Leicester LE3 9QP

9 Pantley GA, Goodnight SH, Rahimtoola S, Harlan BJ, DeMots H, Calvin L, et al. Failure of antiplatelet and anticoagulant therapy to improve patency of grafts after coronary artery bypass. N Engl F Med 1979;301:962-6.

10 Sharma GVRK, Khuri SF, Josa M, Foiland ED, Parisi AF. The effect of antiplatelet therapy on saphenous vein coronary artery bypass graft patency. Circulation 1983;68(suppl II):218-21.

11 Sethi GK, Copeland JG, Goldman S, Moritz T, Zadina K, Henderson WG. Implications of preoperative administration of aspirin in patients undergoing coronary artery bypass grafting. $\mathcal{I} \mathrm{Am}$ Coll Cardiol 1990;15:15-20.

12 Goldman S, Copeland JG, Moritz T, Henderson WG, Zadina K, Ovitt T, et al. Starting aspirin therapy after operation: effects on early graft patency. Circulation 1991;84:520-6.

13 Gavaghan TP, Gebski V, Baron DW. Immediate post-operative aspirin improves vein graft patency early and late after coronary artery bypass graft surgery. Circulation 1991;83:1526-33.

14 McCollum C, Alexander C, Kenchington G, Franks PJ, Greenhalgh R. Antiplatelet drugs in femoropopliteal vein bypasses: a multicentre trial. $f$ Vasc Surg 1991;13:150-62.

15 Dormandy J, Mahir M, Ascady G. Fate of the patient with chronic leg ischemia. 9 Cardiovasc Surg 1989;30:50-7.

16 Collins R, Scrimgeour A, Yusuf S, Peto R. Reduction in fatal pulmonary embolism and venous thrombosis by peri-operative administration of subcutaneous heparin. $N$ Engl F Med 1988;318: 1162-73.

\section{Who benefits from medical interventions?}

\section{Treating low risk patients can be a high risk strategy}

The results of clinical trials are often expressed in relative terms-for example, a particular treatment reduces the risk of an adverse outcome by $40 \%$. Yet knowing that the treatment reduces the risk of such an outcome from 5\% to $3 \%$ (an absolute reduction of $2 \%$ ) may be more useful clinically. ${ }^{1}$

The effects of antiplatelet treatment are a case in point. The meta-analysis of randomised controlled trials of such treatments by the Antiplatelet Trialists' Collaboration shows that the risk of dying from a vascular cause varies substantially according to patient group (p 81). ${ }^{2}$ It ranges from $10 \%$ over one month for patients with an acute myocardial infarction at entry to the trial, through $9 \%$ over two years for those who had survived an acute myocardial infarction, down to only $2 \%$ over five years in trials of primary prevention.

With such varying risks of future vascular events it is unsurprising that the absolute effects of antiplatelet agents differ substantially by patient group. Reductions in relative risks may be similar-antiplatelet drugs reduce the risk of future non-fatal myocardial infarction by $30 \%$ in trials of both primary and secondary prevention. But when the results are presented as the number of patients who need to be treated for one non-fatal myocardial infarction to be avoided they look very different.
In secondary prevention 50 patients need to be treated for two years, while in primary prevention 200 patients need to be treated for five years, for one non-fatal myocardial infarction to be prevented. In other words, it takes 100 patient-years of treatment in secondary prevention or 1000 patient-years of treatment in primary prevention to produce the same beneficial outcome of one fewer non-fatal myocardial infarction.

The fact that the risk that patients are at before they begin treatment affects their absolute benefits from treatment has been much discussed with regard to the treatment of hypertension. ${ }^{3-5}$ In randomised controlled trials treatment has consistently reduced the risk of stroke by $40 \%$ (expressed in relative terms). ${ }^{6}$ The 10 -fold variation in stroke rates in patients in these trials, however, leads to the number of patient-years required to prevent one stroke ranging from around 100 to 1000 . To prevent one vascular death the equivalent figures are about double these. The baseline characteristics of patients-age, sex, blood pressure, other risk factors for cardiovascular disease, and end organ damage - can discriminate groups with widely differing risks of stroke and coronary heart disease. The balance between the benefits and side effects of treatment will be more 